Check for updates

Cite this: RSC Adv., 2018, 8, 25489

\title{
Dimensionality of luminescent coordination polymers of magnesium ions and 1,1'- ethynebenzene-3,3',5,5'-tetracarboxylic acid modulated by structural inducing agents $\uparrow$
}

\author{
Zhu-Xi Yang, ${ }^{a}$ Yin Qian, ${ }^{a}$ Jing-Wei Yu, ${ }^{a}$ Lu Zhai, (DD *a Wen-Wei Zhang (D) ${ }^{\text {b }}$ \\ and Xiao-Ming Ren*abc
}

Solvothermal reactions of aromatic $1,1^{\prime}$-ethynebenzene-3,3',5,5'-tetracarboxylic acid $\left(\mathrm{H}_{4} \mathrm{EBTC}\right)$ and $\mathrm{Mg}^{2+}$ salts in the presence of different supporting ligands afforded the coordination polymers $\left[\mathrm{Mg}\left(\mathrm{H}_{2} \mathrm{EBTC}\right)(\mathrm{DMF})_{2}\left(\mathrm{H}_{2} \mathrm{O}\right)_{2}\right]$ (1), $\left[\mathrm{Mg}_{3}(\mathrm{HEBTC})_{2}\left(\mathrm{H}_{2} \mathrm{O}\right)_{4}\right]$-solvent (2) and $\left[\mathrm{Mg}_{2}(\mathrm{EBTC})\left(\mathrm{H}_{2} \mathrm{O}\right)_{5}\right]$ - solvent (3). The crystal structures of 1-3 were determined by the single crystal X-ray diffraction technique, where CP 1 showed a one-dimensional zigzag $\mathrm{MgO}_{6}$ coordination octahedral chain structure; 2 exhibited a twodimensional $\mathrm{MgO}_{6}$ coordination octahedral framework with trinuclear $\left[\mathrm{Mg}_{3}(\mathrm{COO})_{6}\right] \mathrm{SBUs}$, and 3 featured a three-dimensional $\mathrm{MgO}_{6}$ coordination octahedral framework with binuclear $\left[\mathrm{Mg}_{2} \mathrm{O}(\mathrm{COO})_{2}\right] \mathrm{SBUs}$. The various structures in CPs $1-3$ of $\mathrm{Mg}^{2+}$ ions with the $\mathrm{H}_{4}$ EBTC ligand were ascribed to the conformational flexibility and the coordination mode diversity of the $\mathrm{H}_{4} \mathrm{EBTC}$ ligand. Interestingly, the zwitterionic supporting ligand 2-aminoterephthalic acid or 4-aminobenzenesulphonic acid played a vital role in the initial formation process of nuclear crystals but only as a structural induction agent, which modulated the dimensionality of these $\mathrm{Mg}^{2+}$-based CPs. Additionally, the three CPs emitted bright blue luminescence at ambient conditions, and the emission lifetimes and absolute quantum yields were also investigated.

Received 7th June 2018

Accepted 3rd July 2018

DOI: $10.1039 / c 8 r a 04875 d$

rsc.li/rsc-advances the central metal ion (electron configuration and ionic radius, which predominate the coordination geometry and coordination number of a metal ion), ratio of metal ion to ligand, $\mathrm{pH}$ of the reaction solution, anion type of the metal salt in the starting materials and supporting ligand or template as well as the reaction temperature and time. ${ }^{6-15}$ In most cases, a subtle change in one of the factors mentioned above can lead to a drastic change in the dimensionality and topology of the final crystalline product; unfortunately, it is unclear how the subtle change in a certain factor in a solvothermal process plays a role in the dimensionality and topology of the final product. Particularly, the effect of a supporting ligand or template on the structural transformation still remains largely unexplored to date. For the crystal engineering of CPs, undoubtedly, it is rather important to better understand the mechanism by which a certain factor affects the crystal structure of the product.

It is well-known that an aromatic multicarboxylic acid ligand possesses several $\mathrm{COOH}$ groups in a molecule and in general, these $\mathrm{COOH}$ groups not only adopt abundant coordination modes, but also show a tunable degree of deprotonation. Such a unique structure and binding features of an aromatic multicarboxylic acid ligand usually give rise to crystal structure diversity of the final CP product. ${ }^{16-18}$ It is also worth noting that the introduction of a supporting ligand in the solvothermal 
reaction system can result in a dramatic change in the crystal structure of the final CP product; the supporting ligand acts as the auxiliary ligand in some cases, but it only serves as a template (or a structural induction agent, abbr. as SIA) in other cases. ${ }^{19,20}$ In the second situation, the role played by SIA in the initial formation and growth of nuclear crystals is unclear, and this deserves further study.

In the field of CPs, alkaline earth-metal-based CPs represent an important subcategory of CPs with interesting structures and fascinating physical properties. ${ }^{21}$ With respect to the transition/ rare earth metal-based CPs, the alkaline earth-metal-based CPs have a series of advantages such as low/no toxicity and low cost due to their abundance in earth; ${ }^{22}$ however, they have received less attention. ${ }^{23}$ As a cheap and abundant ion source, the alkaline earth metal ions with a closed-shell electronic configuration are suitable for the preparation of luminescent CPs that have the characteristics of ligand emission. ${ }^{24}$ In this regard, we have been exploring the synthesis approach and photoluminescence properties of CPs of $\mathrm{Mg}^{2+}$ ion with the $\pi$-electron-rich alkynefunctionalized tetracarboxylic acid ligand 1,1'-ethynebenzene$3,3^{\prime}, 5,5^{\prime}$-tetracarboxylic acid $\left(\mathrm{H}_{4} \mathrm{EBTC}\right){ }^{25}$ previous studies have demonstrated that when the $\mathrm{H}_{4}$ EBTC ligand is partly or fully deprotonated, it can act as an excellent phosphor, and it simultaneously emits ligand-based fluorescence and phosphorescence within a colorless $\mathrm{Mg}^{2+}$-based $\mathrm{CP}$ at room temperature. ${ }^{25}$

We aim at further exploring and better understanding the self-assembly behaviors of $\mathrm{Mg}^{2+}$ ions with an excellent luminescence ligand $\mathrm{H}_{4}$ EBTC in the presence of a supporting ligand under solvothermal conditions. Fortunately, by adjusting the reaction temperatures and with or without the help of a supporting ligand, we have successfully obtained three CPs of $\mathrm{Mg}^{2+}$ ion with the $\mathrm{H}_{4}$ EBTC ligand having different degrees of deprotonation, and the CPs are $\left[\mathrm{Mg}\left(\mathrm{H}_{2} \mathrm{EBTC}\right)(\mathrm{DMF})_{2}\left(\mathrm{H}_{2} \mathrm{O}\right)_{2}\right]$ (1), $\left[\mathrm{Mg}_{3}(\mathrm{HEBTC})_{2}\left(\mathrm{H}_{2} \mathrm{O}\right)_{4}\right] \cdot(\mathrm{DMF})_{3}\left(\mathrm{H}_{2} \mathrm{O}\right)_{5}$ (2) and $\left[\mathrm{Mg}_{2}(\mathrm{EBTC})\left(\mathrm{H}_{2^{-}}\right.\right.$ $\left.\mathrm{O})_{5}\right] \cdot(\mathrm{DMF})\left(\mathrm{H}_{2} \mathrm{O}\right)(3)$ (Scheme 1). It is found that SIA plays an important role in modulating the dimensionality of CPs, and the partly/fully deprotonated $\mathrm{H}_{4}$ EBTC ligand shows diverse coordination modes with $\mathrm{Mg}^{2+}$ ions and emits bright blue fluorescence in the three CPs at an ambient temperature.

\section{Experimental section}

\section{Reagents and materials}

All reagents and materials are of analytical grade and used as received from commercial sources without further purification. $\mathrm{H}_{4}$ EBTC was synthesized according to the method published. ${ }^{26}$

\section{Chemical analysis and physical measurements}

IR spectra were obtained on a NICOLET iS10 spectrometer in the $4000-400 \mathrm{~cm}^{-1}$ region. Powder X-ray diffraction (PXRD) data were recorded on a Bruker D8 Discover diffractometer with $\mathrm{Cu}$ $\mathrm{K} \alpha(\lambda=1.54056 \AA)$ radiation and a scan speed of $5^{\circ} \mathrm{min}^{-1}$ and a step size of $0.02^{\circ}$ in $2 \theta$. Elemental analyses of $\mathrm{C}, \mathrm{H}$, and $\mathrm{N}$ were determined using a PerkinElmer 2400C automatic analyzer. The luminescent images were obtained using a Nikon polarizing optical microscope (NIS-Elements Documentation) equipped with an ultraviolet light source $\left(\lambda_{\mathrm{ex}}=330-380 \mathrm{~nm}\right)$. Thermal gravimetric analyses (TGA) were performed using a DTA-TGA 2960 thermogravimetric analyzer in a nitrogen atmosphere with a heating rate of $10{ }^{\circ} \mathrm{C} \mathrm{m^{-1 }}$ from 25 to $800{ }^{\circ} \mathrm{C}$.

Steady state emission and excitation spectra were recorded for the solid samples on an F-7000 FL spectrofluorometer equipped with a $150 \mathrm{~W}$ Xenon lamp as an excitation source at room temperature. The photomultiplier tube (PMT) voltage was $700 \mathrm{~V}$ for all measurements. The scan speed was 1200 $\mathrm{nm} \min ^{-1}$. The room temperature luminescence study was performed on a Fluorolog-3-TAU fluorescence spectrophotometer. The fluorescence lifetime measurement was obtained by a single-photon counting spectrometer using an Edinburgh FLP920 spectrometer equipped with a continuous Xe900 xenon lamp. Absolute photoluminescence quantum yields were measured on a Steady-State and Time-Resolved Fluorescence Spectrofluorometer.
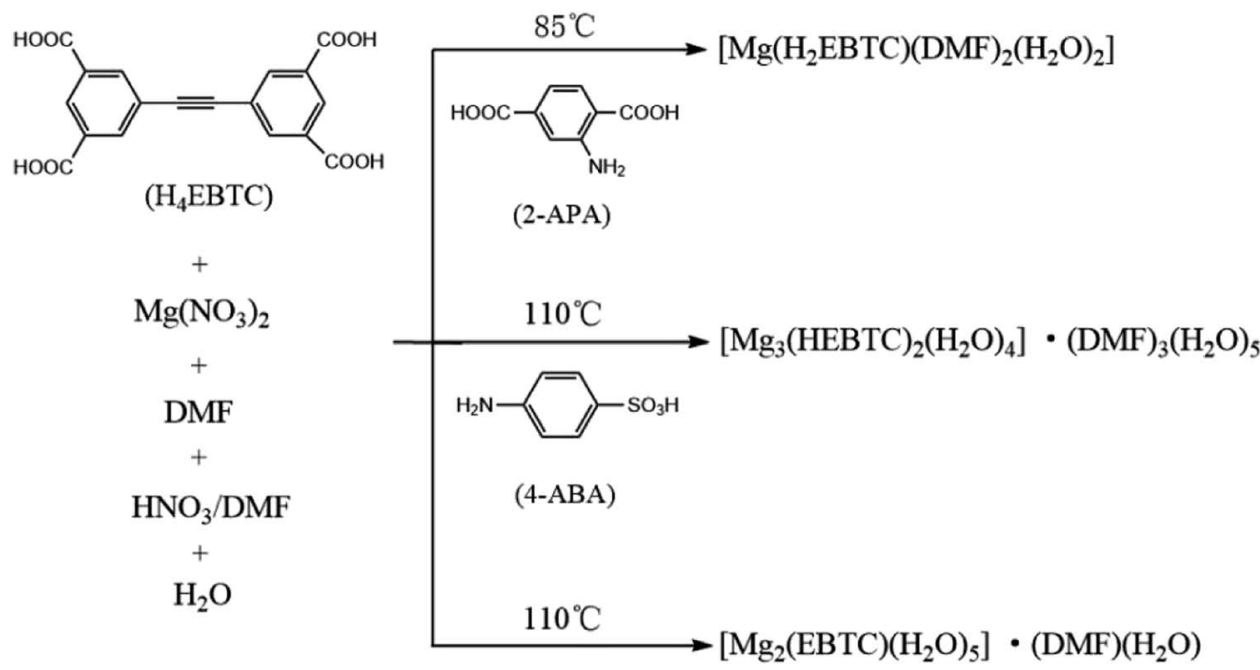

(1) 


\section{Preparation of 1-3}

$\left[\mathrm{Mg}\left(\mathrm{H}_{2}\right.\right.$ EBTC $\left.)(\mathrm{DMF})_{2}\left(\mathrm{H}_{2} \mathrm{O}\right)_{2}\right]$ (1). A mixed solution containing $\mathrm{Mg}\left(\mathrm{NO}_{3}\right)_{2} \cdot 6 \mathrm{H}_{2} \mathrm{O}$ (8 mg, $\left.0.056 \mathrm{mmol}\right), \mathrm{H}_{4}$ EBTC $(5 \mathrm{mg}, 0.014$ $\mathrm{mmol}$ ), 2-aminoterephthalic acid (2-APA) (3 $\mathrm{mg}, 0.017 \mathrm{mmol}$ ), DMF (0.4 mL), $\mathrm{CH}_{3} \mathrm{OH}(0.10 \mathrm{~mL}), \mathrm{HNO}_{3}(0.04 \mathrm{~mL}, 1 \mathrm{M}$ in DMF) and $\mathrm{H}_{2} \mathrm{O}(0.10 \mathrm{~mL})$ was sealed in a $10 \mathrm{~mL}$ Teflon-lined autoclave and heated to $85{ }^{\circ} \mathrm{C}$ for $24 \mathrm{~h}$. Colorless block-shaped crystals were achieved after the Teflon-lined autoclave slowly cooled to an ambient temperature (yield: $c a$. $58 \%$ based on $\mathrm{H}_{4}$ EBTC). Anal. elemental analysis: calcd for $\mathrm{C}_{24} \mathrm{H}_{26} \mathrm{MgN}_{2} \mathrm{O}_{12}$ : C, 51.58; $\mathrm{H}$, 4.69; N, 5.01. Found: C, 51.62; H, 4.98; N, 5.56. Selected IR data (KBr pellet, $\mathrm{cm}^{-1}$ ): 3360 (b), 1567 (m), 1432 (m), 1378 (s), 1101 (m), $775(\mathrm{w}), 704(\mathrm{w})$.

$\left[\mathrm{Mg}_{3}(\mathrm{HEBTC})_{2}\left(\mathrm{H}_{2} \mathrm{O}\right)_{4}\right] \cdot(\mathrm{DMF})_{3}\left(\mathrm{H}_{2} \mathrm{O}\right)_{5}$ (2). A mixed solution with $\mathrm{Mg}\left(\mathrm{NO}_{3}\right)_{2} \cdot 6 \mathrm{H}_{2} \mathrm{O}$ (8 mg, $\left.0.056 \mathrm{mmol}\right), \mathrm{H}_{4}$ EBTC (5 mg, 0.014 $\mathrm{mmol}$ ), 4-aminobenzenesulphonic acid (4-ABA) (3 mg, 0.017 $\mathrm{mmol}), \mathrm{DMF}(0.4 \mathrm{~mL}), \mathrm{CH}_{3} \mathrm{OH}(0.10 \mathrm{~mL}), \mathrm{HNO}_{3}(0.04 \mathrm{~mL}, 1 \mathrm{M}$ in DMF) and $\mathrm{H}_{2} \mathrm{O}(0.10 \mathrm{~mL})$ was sealed in a $10 \mathrm{~mL}$ Teflon-lined autoclave and heated to $110{ }^{\circ} \mathrm{C}$ for $24 \mathrm{~h}$. Colorless blockshaped crystals were achieved after the Teflon-lined autoclave slowly cooled to room temperature (yield: $c a$. $60 \%$ based on $\mathrm{H}_{4}$ EBTC). Anal. elemental analysis: calcd for $\mathrm{C}_{36} \mathrm{H}_{22} \mathrm{Mg}_{3} \mathrm{O}_{20}$ : C, 46.72; H, 4.62; N, 3.63. Found: C, 46.35; H, 4.66; N, 3.23. Selected IR data (KBr pellet, $\left.\mathrm{cm}^{-1}\right): 3207$ (b), $1557(\mathrm{~m}), 1428(\mathrm{~m})$, 1366 (s), 1102 (m), 777 (w), $711(\mathrm{w})$.

$\left[\mathbf{M g}_{2}(\mathbf{E B T C})\left(\mathbf{H}_{2} \mathbf{O}\right)_{5}\right] \cdot(\mathrm{DMF})\left(\mathrm{H}_{2} \mathbf{O}\right)$ (3). A mixed solution with $\mathrm{Mg}\left(\mathrm{NO}_{3}\right)_{2} \cdot 6 \mathrm{H}_{2} \mathrm{O}$ (8 mg, $0.056 \mathrm{mmol}$ ), $\mathrm{H}_{4}$ EBTC (5 mg, 0.014 $\mathrm{mmol}), \mathrm{DMF}(0.4 \mathrm{~mL}), \mathrm{CH}_{3} \mathrm{OH}(0.10 \mathrm{~mL}), \mathrm{HNO}_{3}(0.04 \mathrm{~mL}, 1 \mathrm{M}$ in DMF) and $\mathrm{H}_{2} \mathrm{O}(0.10 \mathrm{~mL})$ was sealed in a $10 \mathrm{~mL}$ Teflon-lined autoclave and heated to $110{ }^{\circ} \mathrm{C}$ for $24 \mathrm{~h}$. Colorless blockshaped crystals were achieved after the Teflon-lined autoclave slowly cooled to room temperature (yield: $c a$. $60 \%$ based on $\mathrm{H}_{4}$ EBTC). Anal. Elemental analysis: calcd for $\mathrm{C}_{18} \mathrm{H}_{16} \mathrm{Mg}_{2} \mathrm{O}_{13}: \mathrm{C}$,
43.48; H, 2.41; N, 4.34. Found: C, 43.20; H, 2.27; N, 4.33. Selected IR data (KBr pellet, $\mathrm{cm}^{-1}$ ): 3226 (b), 1567 (m), 1430 (m), 1361 (s), 1104 (m), 772 (w), 705 (w).

\section{Crystallographic analyses}

Suitable single crystals of 1-3 were selected under an optical microscope and glued to thin glass fibers. Single crystal X-ray diffraction data were obtained on a Bruker Smart Apex II CCD diffractometer using graphite monochromated $\mathrm{Mo} / \mathrm{K} \alpha$ radiation $(\lambda=0.71073 \AA)$. Data reductions and absorption corrections were performed with the SAINT ${ }^{27}$ and SADABS2 (ref. 28) software packages, respectively. Structures were solved by a direct method using the SHELXL software package. ${ }^{29}$ The non-hydrogen atoms were anisotropically refined using the full-matrix least-squares method on $F^{2}$. All hydrogen atoms were placed at the calculated positions and refined riding on the parent atoms. In the crystal structure of $\mathbf{1}$, one of the two crystallographically different DMF molecules showed disorder, and the corresponding atoms were refined using split-atom models; the occupied site factor was refined. In the crystal structures of $\mathbf{2}$ and 3, the frameworks contained severely disordered lattice solvents, and the large volume fractions of the disordered solvents in the lattices could not be modeled in terms of atomic sites and were treated using the SQUEEZE routine in the PLATON software package. ${ }^{30}$ The solvents were accounted for both 2 and 3 using SQUEEZE ${ }^{31}$ implemented in PLATON, which calculates the electron densities in the unit cells and accounts for them in the refinement. This electron density was assigned as some specific solvent content.

CCDC 1838042 (1), 1573136 (2) and 1573138 (3) contain the supplementary crystallographic data for this paper. The crystallographic data and details of structural refinements are listed in Table 1, and the selected bond distances and angles are listed in Table $\mathrm{S} 1$ in the ESI† for 1-3.

Table 1 Crystallographic data and structure refinement for 1-3

\begin{tabular}{llll}
\hline Compound & $\mathbf{1}$ & 2 & 3 \\
\hline Formula & $\mathrm{C}_{24} \mathrm{H}_{26} \mathrm{MgN}_{2} \mathrm{O}_{12}$ & $\mathrm{C}_{18} \mathrm{H}_{16} \mathrm{Mg}_{2} \mathrm{O}_{13} \cdot \mathrm{Solvent}$ & 488.93 \\
Formula weight & 558.78 & $\mathrm{C}_{36} \mathrm{H}_{22} \mathrm{Mg}_{3} \mathrm{O}_{20} \cdot$ solvent & 1573138 \\
CCDC no. & 1838042 & 847.46 & $295(2)$ \\
Temp. $(\mathrm{K})$ & $295(2)$ & 1573136 & 0.71073 \\
Wavelength $(\AA)$ & 0.71073 & 0.71073 & $0.15 \times 0.15 \times 0.12$ \\
Crystal size/mm & $0.21 \times 0.18 \times 0.16$ & $0.15 \times 0.15 \times 0.12$ & Monoclinic \\
Crystal system & Monoclinic & Monoclinic & $C 2 / c$ \\
Space group & $P 2_{1} / n$ & $P 2_{1} / c$ & $16.8934(15)$ \\
$a / \AA$ & $8.0079(7)$ & $14.726(2)$ & $14.1990(13)$ \\
$b / \AA$ & $16.8300(15)$ & $15.126(2)$ & $12.0673(11)$ \\
$c / \AA$ & $19.0430(16)$ & $13.5397(18)$ & 90 \\
$\alpha / \AA$ & 90 & 90 & $115.993(2)$ \\
$\beta / \AA$ & $100.254(2)$ & $116.871(6)$ & 90 \\
$\gamma / \AA$ & 90 & 90 & $2601.8(4)$ \\
$V / \AA^{3}$ & $2525.5(4)$ & $2690.3(6)$ & 4 \\
$Z$ & 4 & 2 & 1008 \\
$F(000)$ & 1168 & 868 & $3.097,27.602$ \\
$\theta_{\text {min,max }} /_{\mathrm{GOF}}^{\circ}$ & $2.854,25.388$ & $3.070,27.641$ & 1.030 \\
$R_{1}, \mathrm{w} R_{2}[I>2 \sigma(I)]^{a}$ & 1.083 & 0.996 & $0.0592,0.1554$
\end{tabular}

${ }^{a} R_{1}=\sum|| F_{0}|-| F_{\mathrm{c}}\left|/ / \sum\right| F_{0} \mid$ and $\mathrm{w} R_{2}=\left\{\sum\left[\mathrm{w}\left(F_{0}{ }^{2}-F_{\mathrm{c}}{ }^{2}\right)^{2}\right] / \sum\left[\mathrm{w}\left(F_{0}{ }^{2}\right)^{2}\right]\right\}^{1 / 2}$. 


\section{Results and discussion}

\section{Preparation of CPs}

CP 1, $\left[\mathrm{Mg}\left(\mathrm{H}_{2} \mathrm{EBTC}\right)(\mathrm{DMF})_{2}\left(\mathrm{H}_{2} \mathrm{O}\right)_{2}\right]$, was obtained under the same reaction conditions as those used for the preparation of a $\mathrm{Mg}$ based $\mathrm{CP},\left[\mathrm{Mg}\left(\mathrm{H}_{2} \mathrm{EBTC}\right)(\mathrm{DMF})_{2}\right]$, which we previously reported ${ }^{25}$ except that 2-aminoterephthalic acid (2-APA) was added during the synthesis of $\mathbf{1}$. In addition, CP $\mathbf{2}$ and $\mathbf{3}$ were also generated under the same solvothermal conditions but with an elevated temperature of $110{ }^{\circ} \mathrm{C}$, and the difference between the preparation processes of 2 and 3 is that only 4-aminobenzenesulphonic acid (4-ABA) was added during the synthesis of 2 . Notably, it is not possible to achieve 1 (or 2) but instead only $\left[\mathrm{Mg}\left(\mathrm{H}_{2}\right.\right.$ EBTC)(DMF) $\left.{ }_{2}\right]^{25}$ (or 3) is formed in the absence of 2-APA (or 4ABA) during the reaction process. These findings indicated that 2-APA and 4-ABA induced the formation of the crystal structures of $\mathbf{1}$ and $\mathbf{2}$ in the corresponding solvothermal reactions and acted as SIAs in the crystal growth process.

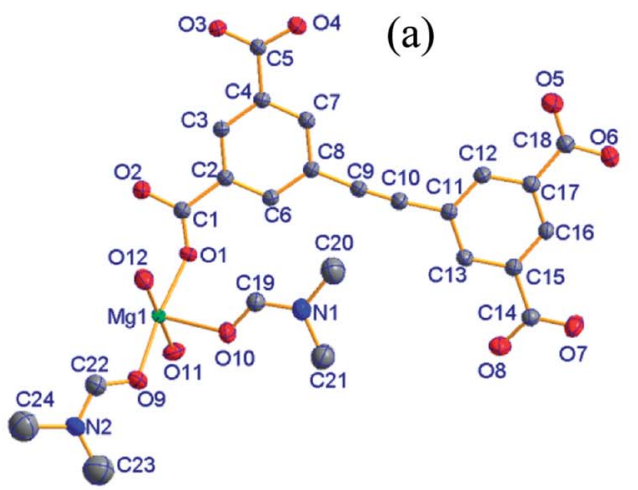

(c)
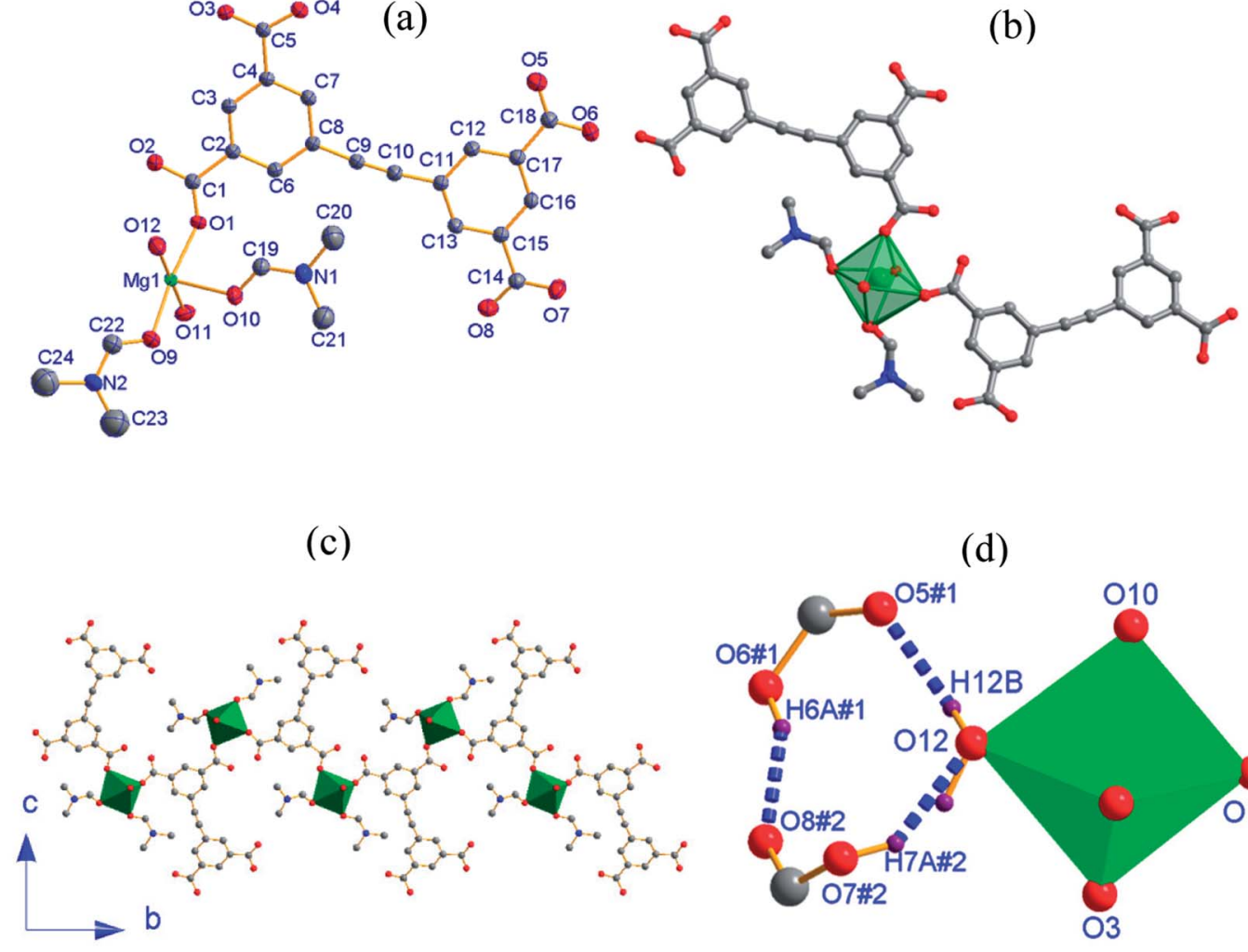

(d)

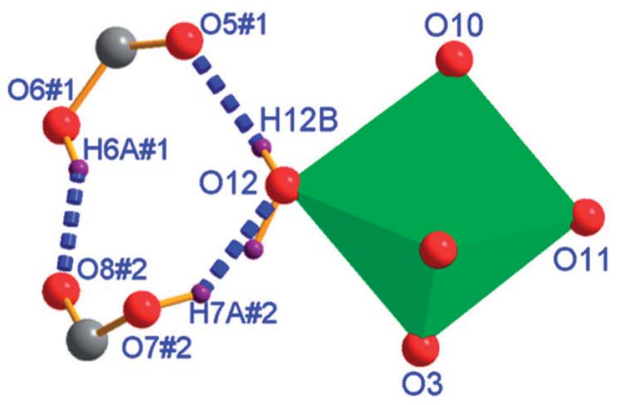

(f)

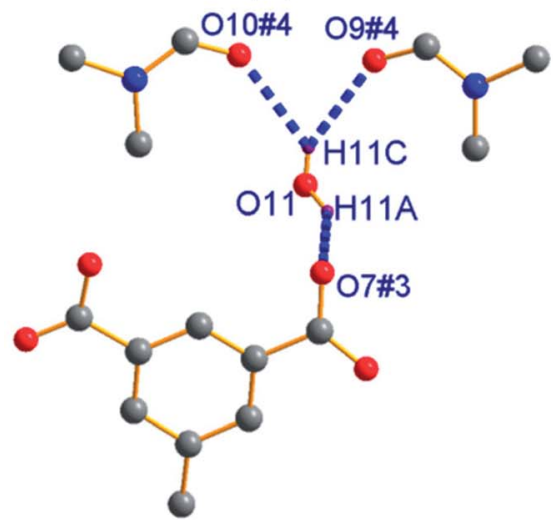

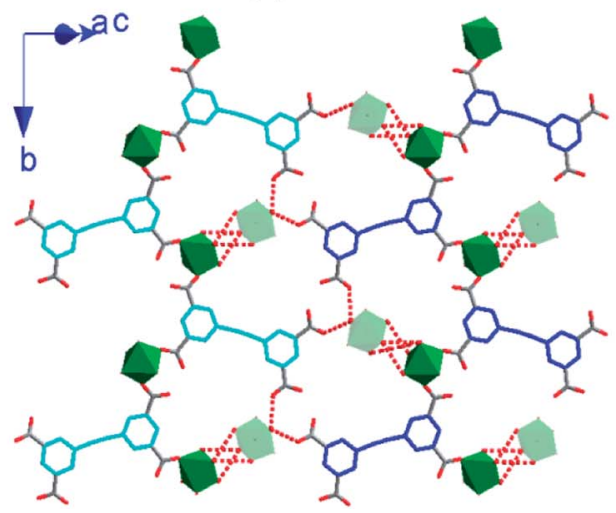

Fig. 1 (a) An asymmetric unit of 1 with thermal ellipsoids at 50\% probability level where one coordinated DMF molecule is disordered; (b) the coordination environment around the $\mathrm{Mg}^{2+}$ ion; (c) 1-D chain structure where the disordered methyl groups in DMF are omitted for clarity; (d) $\mathrm{H}$ bonds between the $\mathrm{H}_{2} \mathrm{O}$ molecule with $\mathrm{O} 12$ and $\mathrm{COO}^{-}$groups; (e) $\mathrm{H}$-bonds between the $\mathrm{H}_{2} \mathrm{O}$ molecule with $\mathrm{O}_{11}$ and $\mathrm{COO}^{-}$groups as well as the $\mathrm{O}$ atoms of DMF molecules; (f) molecular layers formed via $\mathrm{H}$-bonding interactions (the symmetric codes in (d and e): \#1=1-x, $1-y, 1-z$; $\# 2=1.5+x, 0.5-y,-0.5+z ; \# 3=-0.5+x, 0.5-y,-0.5+z ; \# 4=1-x,-y, 1-z)$. 


\section{Crystal structures}

CP 1, $\left[\mathrm{Mg}\left(\mathrm{H}_{2}\right.\right.$ EBTC $\left.)(\mathrm{DMF})_{2}\left(\mathrm{H}_{2} \mathrm{O}\right)_{2}\right]$, crystallizes in the monoclinic space group $P 22_{1} / n$ with the formula of $\mathrm{C}_{24} \mathrm{H}_{26} \mathrm{MgN}_{2} \mathrm{O}_{12}$. As shown in Fig. 1a, its asymmetric unit contains one $\mathrm{Mg}^{2+}$ ion, one $\mathrm{H}_{2}$ EBTC $^{2-}$ ligand together with two differently coordinated water molecules and two crystallographically inequivalent coordinated DMF molecules. One of the two distinct DMF molecules containing $\mathrm{O} 9$ is disordered with two possible positions, and the occupied factors are refined for each possible position. The $\mathrm{Mg}^{2+}$ ion is six-coordinated by oxygen atoms, in which two oxygen atoms are obtained from two $\mathrm{H}_{2} \mathrm{EBTC}^{2-}$ ligands (where two $\mathrm{COO}^{-}$groups adopt the $\eta^{1}$ binding mode), two are obtained from two terminal DMF molecules and the other two from two $\mathrm{H}_{2} \mathrm{O}$ molecules, presenting a distorted octahedral geometry (Fig. 1b). The oxygen atoms from the two crystallographically different DMF molecules and the two oxygen atoms from the two crystallographically equivalent $\mathrm{H}_{2} \mathrm{EBTC}^{2-}$ ligands lie in the equatorial plane of the coordination octahedron of $\mathrm{MgO}_{6}$. Two DMF molecules and two $\mathrm{H}_{2} \mathrm{EBTC}^{2-}$ ligands adopt a cis arrangement, whereas the two crystallographically different water molecules are located in two axial positions of the coordination octahedron of $\mathrm{MgO}_{6}$ in a trans fashion (ref. Fig. $1 \mathrm{~b}$ ). The $\mathrm{Mg}-\mathrm{O}$ bond lengths range from 2.055(4) to 2.092(3) $\AA$, and the $\mathrm{O}-\mathrm{Mg}-\mathrm{O}$ bond angles range from $85.72(15)$ to $99.16(14)^{\circ}$ with two coordinated oxygen atoms in a cis arrangement; the bond angles also range from 172.88(15) to $179.21(17)^{\circ}$ with two coordinated oxygen atoms in a trans arrangement in the $\mathrm{MgO}_{6}$ coordination octahedron. In the previously reported crystal structure of $\left[\mathrm{Mg}\left(\mathrm{H}_{2} \mathrm{EBTC}\right)(\mathrm{DMF})_{2}\right],{ }^{25}$ two coordinated DMF molecules also remain in the cis coordination sites in the $\mathrm{MgO}_{6}$ coordination octahedron; this is similar to that in 1. Notably, the $\mathrm{O}-\mathrm{Mg}-\mathrm{O}$ bond angles span from $87.05(6)$ to $98.23(6)^{\circ}$ with two coordinated oxygen atoms in a cis arrangement and from $172.36(6)$ to $172.42(8)^{\circ}$ with two coordinated oxygen atoms in a trans arrangement in the $\mathrm{MgO}_{6}$ coordination octahedron, showing more narrow distribution than those in 1; the Mg-O bond distances vary from 2.070(18) to 2.102(20) $\AA$ and are slightly longer than those in 1. The steric hindrance between the four $\eta^{1}$-binding mode $\mathrm{COO}^{-}$groups around the $\mathrm{Mg}^{2+}$ center probably corresponds to the fact that $\left[\mathrm{Mg}\left(\mathrm{H}_{2} \mathrm{EBTC}\right)(\mathrm{DMF})_{2}\right]$, as previously reported, has longer $\mathrm{Mg}-\mathrm{O}$ bond distances than 1 (where there are two $\mathrm{COO}^{-}$groups with $\eta^{1}$ binding mode around the $\mathrm{Mg}^{2+}$ center).

Two phenyl rings in the $\mathrm{H}_{2} \mathrm{EBTC}^{2-}$ ligand are almost coplanar in 1, with a small dihedral angle of $1.3^{\circ}$ (ref. Fig. S2a $\dagger$ ). The $\mathrm{H}_{2}$ EBTC $^{2-}$ anion serves as a $\mu_{2}-\eta^{1}: \eta^{1}$ mode bridged ligand, and its two $\mathrm{COO}^{-}$groups in the same phenyl ring link two $\mathrm{Mg}^{2+}$ ions in the monodentate mode to generate a 1-D zigzag chain along the $b$-axis (Fig. 1c). The H-bonding interactions are observed between the coordinated $\mathrm{H}_{2} \mathrm{O}$ molecules and the coordinated DMF molecules as well as between the coordinated $\mathrm{H}_{2} \mathrm{O}$ molecules and $\mathrm{COO}^{-}$groups; these are displayed in Fig. 1d and e, and the $\mathrm{H}$-bond parameters are listed in Table 2. As depicted in Fig. 1f, the neighboring 1-D zigzag $\mathrm{MgO}_{6}$ coordination octahedral chains, where the corresponding phenyl rings are presented in blue and cyan colors, extend into the 2-D
Table 2 Parameters of $\mathrm{H}$-bonds in $1^{a}$

\begin{tabular}{|c|c|c|c|c|}
\hline $\mathrm{D}-\mathrm{H} \cdots \mathrm{A}$ & $\mathrm{D}-\mathrm{H} / \mathrm{A}$ & $\mathrm{H} \cdots \mathrm{A} / \AA$ & $\mathrm{D} \cdots \mathrm{A} / \mathrm{A}$ & $\angle \mathrm{D}-\mathrm{H} \cdots \mathrm{A} /{ }^{\circ}$ \\
\hline $\mathrm{O} 12-\mathrm{H} 12 \mathrm{~B} \cdots \mathrm{O}$ \#\#1 & 0.85 & 2.25 & $2.708(4)$ & 114 \\
\hline $\mathrm{O} 6 \# 1-\mathrm{H} 6 \mathrm{~A} \# 1 \cdots \mathrm{O} 8 \# 2$ & 0.82 & 1.75 & $2.475(4)$ & 146 \\
\hline $\mathrm{O} 7 \# 2-\mathrm{H} 7 \mathrm{~A} \# 2 \cdots \mathrm{O} 12$ & 0.85 & 1.94 & $2.648(4)$ & 144 \\
\hline O11-H11A $\cdots \mathrm{O} 7 \# 3$ & 0.95 & 1.92 & $2.768(4)$ & 148 \\
\hline O11-H11C $\cdots$ O9\#4 & 0.79 & 2.41 & $3.095(4)$ & 146 \\
\hline O11-H11C $\cdots \mathrm{O} 10 \# 4$ & 0.79 & 2.44 & $3.084(4)$ & 139 \\
\hline
\end{tabular}

supramolecular layer via intermolecular $\mathrm{H}$-bonds, and this type of a 2-D supramolecular layer is parallel to the crystallographic $\left(\begin{array}{ll}1 & 0\end{array}-1\right)$ plane. The adjacent supramolecular layers are further connected to the 3-D framework through $\mathrm{H}$-bonds between the coordinated $\mathrm{H}_{2} \mathrm{O}$ molecules with $\mathrm{O} 11$ in $\mathrm{MgO}_{6}$ (green color) and the $\mathrm{O}$ atoms in DMF molecules with $\mathrm{O} 9$ and $\mathrm{O} 10$ of the neighboring $\mathrm{MgO}_{6}$ (light green color) along the $<10-1>$ direction, which is shown in Fig. 1f.

2, $\left[\mathrm{Mg}_{3}(\mathrm{HEBTC})_{2}\left(\mathrm{H}_{2} \mathrm{O}\right)_{4}\right] \cdot(\mathrm{DMF})_{3}\left(\mathrm{H}_{2} \mathrm{O}\right)_{5}$, crystallizes in the monoclinic space group $P 2_{1} / n$ with the formula $\mathrm{C}_{36} \mathrm{H}_{22} \mathrm{Mg}_{3} \mathrm{O}_{20}$. As shown in Fig. 2a, its asymmetric unit consists of two crystallographically independent $\mathrm{Mg}^{2+}$ ions (labeled as $\mathrm{Mg} 1$ and $\mathrm{Mg} 2$ ) and one partly deprotonated HEBTC ${ }^{3-}$ ligand together with two coordinated water molecules as well as heavy disordered lattice solvents. Mg1 is located at a general position, whereas Mg2 occupies an inversion center. Both Mg1 and Mg2 are coordinated with six oxygen atoms; however, they show significantly different coordination environments. The Mg1 coordination sphere can be viewed as a distorted octahedron, where four coordinated oxygen atoms are obtained from three carboxylates in three HEBTC $^{3-}$ ligands, and the other two coordinated oxygen atoms are provided by two dangling coordinated water molecules. As depicted in Fig. 2b, two coordinated water molecules adopt a cis arrangement in the $\mathrm{MgO}_{6}$ coordination octahedron with $\mathrm{Mg}$. The $\mathrm{Mg} 2$ coordination sphere displays regular octahedral geometry with $C_{\mathrm{i}}$ point group symmetry, and six coordinated oxygen atoms are obtained from six carboxylates in six different HEBTC $^{3-}$ ligands (Fig. S3b $\dagger$ ). The Mg-O distances range from 1.965(3) to 2.211(3) $\AA$ in the coordination octahedron with $\mathrm{Mg} 1$ and from 2.028(3) to 2.144(2) $\AA$ in the coordination octahedron with $\mathrm{Mg} 2$; the O-MgO bond angles range from $60.03(10)$ to $102.05(1)^{\circ} / 161.17(13)$ to $177.45(16)^{\circ}$ with two $\mathrm{O}$ atoms in cis/trans arrangements in $\mathrm{MgO}_{6}$ containing $\mathrm{Mg} 1$ versus $87.07(10)-92.93(10)^{\circ} / 180^{\circ}$ with two $\mathrm{O}$ atoms in cis/trans arrangements in $\mathrm{MgO}_{6}$ containing $\mathrm{Mg} 2$. These parameters in the $\mathrm{MgO}_{6}$ coordination octahedra are comparable to the values of the $\mathrm{Mg}^{2+}$-carboxylate coordination compounds previously reported. ${ }^{25}$

In the crystal structure of 2, as shown in Fig. 2b, each $\mathrm{Mg} 2$ ion is bridged to two neighboring $\mathrm{Mg} 1$ ions by four $-\mathrm{O}-\mathrm{C}-\mathrm{O}-$ bridges and two $\mu_{2}-\mathrm{O}_{\text {carboxyl }}$ atoms to afford a centrosymmetric trinuclear $\left\{\mathrm{Mg}_{3}\right\}$ cluster as secondary building unit (SBU), where three $\mathrm{Mg}^{2+}$ ions are strictly linear because $\mathrm{Mg} 2$ is located at an inversion center; the Mg1 $\cdots \mathrm{Mg} 2$ distance is $3.602 \AA$. As shown in Fig. S2b, $\dagger$ two phenyl rings in HEBTC $^{3-}$ exhibit a dihedral 

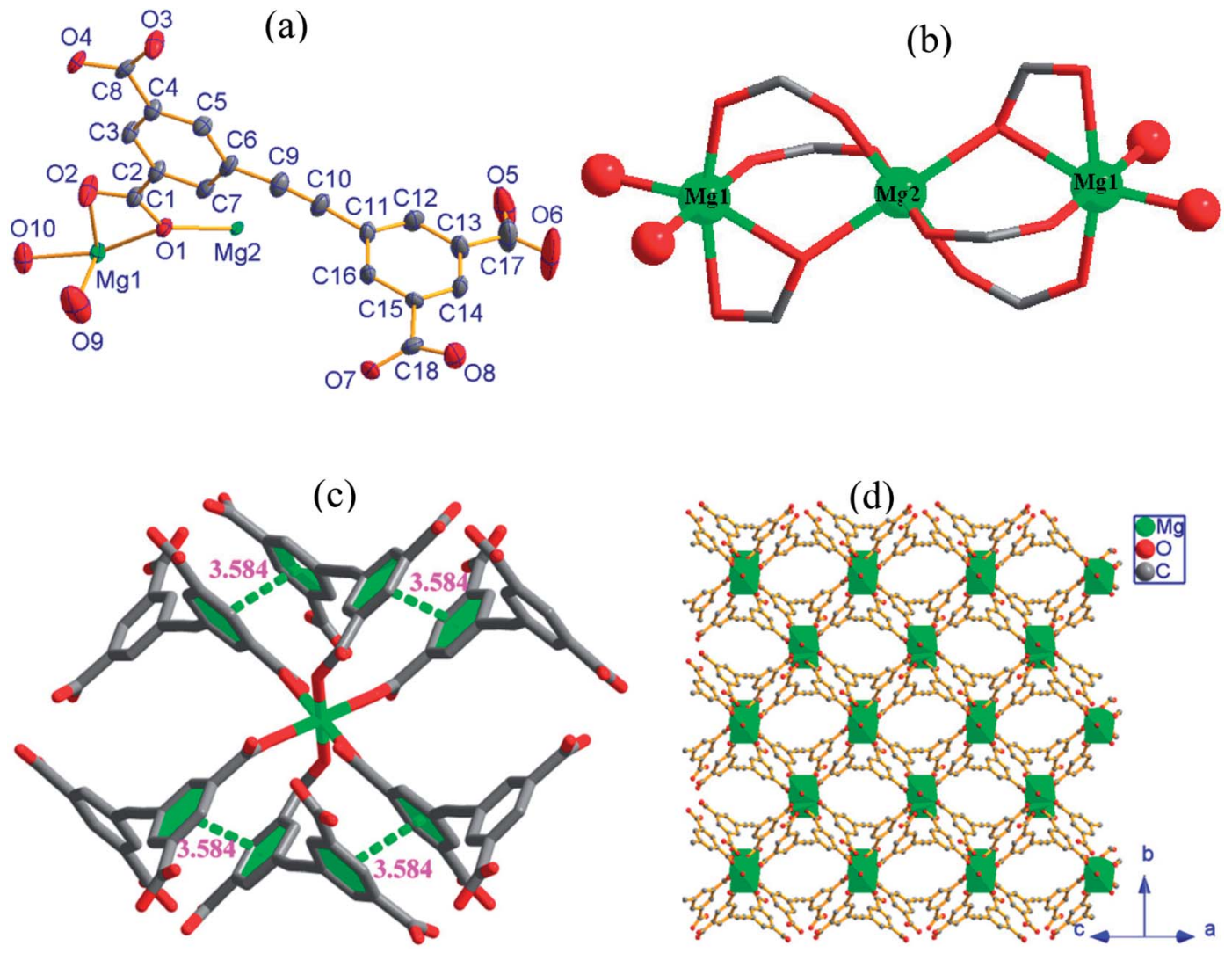

Fig. 2 (a) An asymmetric unit with thermal ellipsoids drawn at 50\% probability level; (b) trinuclear cluster as SBU with magnesium as assigned in the ball model; (c) intramolecular $\pi \cdots \pi$ interactions; (d) 2-D network viewed along the $<101>$ direction (all $\mathrm{H}$ atoms were omitted for clarity) in 2.

angle of $82.3^{\circ}$; this indicates a strong spatial-distortion effect from coordination with $\mathrm{Mg}^{2+}$ ions, presumably to accommodate the steric demands of the dense SBUs. Two of the three $\mathrm{COO}^{-}$ groups adopt $\left(\mu_{2}-\eta^{1}, \eta^{1}\right)$ binding modes to connect one Mg1 and one $\mathrm{Mg} 2$, and the remaining $\mathrm{COO}^{-}$group in the $\mathrm{HEBTC}^{3-}$ ligand shows $\left(\mu_{2}-\eta^{2}, \eta^{1}\right)$ binding mode to coordinate to one Mg1 and one Mg2. Each HEBTC ${ }^{3-}$ ligand links six $\mathrm{Mg}^{2+}$ ions through $\left(\mu_{2}-\eta^{1}, \eta^{1}\right)$ and $\left(\mu_{2}-\eta^{2}, \eta^{1}\right)$ coordination modes, and it also serves as a $\mu_{6}$-bridge linker. As shown in Fig. $2 c$, the neighboring phenyl rings from different $\mathrm{HEBTC}^{3-}$ ligands show face-to-face alignment with a centroid-to-centroid distance of $3.584 \AA$, indicating the existence of $\pi \cdots \pi$ interactions between them. The linear $\left\{\mathrm{Mg}_{3}\right\}$ cluster links six neighbors by six HEBTC $^{3-}$ ligands, and each HEBTC ${ }^{3-}$ ligand connects three adjacent trinuclear SUBs to form a 2-D metal-organic framework, which is parallel to the crystallographic $b c$-plane, as depicted in Fig. 2d. The coordinated $\mathrm{H}_{2} \mathrm{O}$ molecules and the $\mathrm{COOH}$ groups in $\mathrm{HEBTC}^{3-}$ ligands distribute on the surfaces of the 2-D frameworks. The heavy disordered lattice solvent molecules are residual in the pores of the frameworks.

3, $\left[\mathrm{Mg}_{2}(\mathrm{EBTC})\left(\mathrm{H}_{2} \mathrm{O}\right)_{5}\right] \cdot(\mathrm{DMF})\left(\mathrm{H}_{2} \mathrm{O}\right)$, crystallizes in the monoclinic space group $C 2 / c$ with the formula $\mathrm{C}_{18} \mathrm{H}_{16} \mathrm{Mg}_{2} \mathrm{O}_{13}$. As shown in Fig. 3a, its asymmetric unit consists of one $\mathrm{Mg}^{2+}$ ion and half $\mathrm{H}_{2} \mathrm{EBTC}^{2-}$ ligand together with three coordinated water molecules as well as the heavy disordered lattice solvents. The $\mathrm{Mg}^{2+}$ ion is six-coordinated and connected by three oxygen atoms from three different $\mathrm{H}_{2}$ EBTC $^{2-}$ ligands and three oxygen atoms from three $\mathrm{H}_{2} \mathrm{O}$ molecules. Two neighboring $\mathrm{MgO}_{6}$ coordination octahedra share a vertex (O5) to form a binuclear $\left[\mathrm{Mg}_{2} \mathrm{O}(\mathrm{COO})_{2}\right]$ SBU with Mg1 $\cdots \mathrm{Mg} 1$ distance of $3.556 \AA$ A (Fig. 3b).

The EBTC $^{4-}$ ligand shows $C_{2}$ point group symmetry and a two-fold rotation axis parallel to the $b$-axis, which passes through the midpoint of the $\mathrm{C} \equiv \mathrm{C}$ triple bond. The dihedral angle of the two phenyl rings in $\mathrm{EBTC}^{4-}$ is $83.8^{\circ}$, indicating a strong spatial-distortion effect from coordination with the $\mathrm{Mg}^{2+}$ ions to accommodate the steric demands of the dense SBUs (ref. Fig. S2c $\dagger$ ). Four carboxylate groups in the EBTC ${ }^{4-}$ ligand adopt two different coordination modes $\mu_{1}-\eta^{1}: \eta^{0}$ and $\mu_{2}-\eta^{1}: \eta^{1}$ (Fig. 4c). The EBTC ${ }^{4-}$ ligand connects four binuclear $\left[\mathrm{Mg}_{2} \mathrm{O}(\mathrm{COO})_{2}\right]$ SBUs, and the binuclear $\left[\mathrm{Mg}_{2} \mathrm{O}(\mathrm{COO})_{2}\right] \mathrm{SBU}$ connects four $\mathrm{EBTC}^{4-}$ ligands (ref. Fig. 3c) to extend into a 3-D framework, which is displayed in Fig. $3 \mathrm{~d}$ projected along the $c$ axis and Fig. S4b and S4c $\dagger$ viewed along the $b$-axis and the $<1$ $01>$ direction, respectively. The heavy disordered lattice solvent molecules are located in the pores of the 3-D framework.

\section{Diversity of coordination mode of $\mathrm{H}_{4}$ EBTC}

In the crystal structures of 1-3, $\mathrm{H}_{2} \mathrm{EBTC}^{2-} / \mathrm{HEBTC}^{3-} / \mathrm{EBTC}^{4-}$ ligands formed as a result of deprotonation of the $\mathrm{H}_{4}$ EBTC ligand during solvothermal synthesis show diverse coordination modes to that of the $\mathrm{Mg}^{2+}$ ion. As shown in Fig. 4, the $\mathrm{COOH}$ group is uncoordinated to $\mathrm{Mg}^{2+}$ ion (in both 1 and 2), and the deprotonated $\mathrm{COO}^{-}$groups show three types of coordination modes, i.e., monodentate $\mu_{1}-\eta^{1}: \eta^{0}$ in 1 and 3 and bidentate $\mu_{2}-\eta^{1}: \eta^{1}$ in 2 and 3 as 

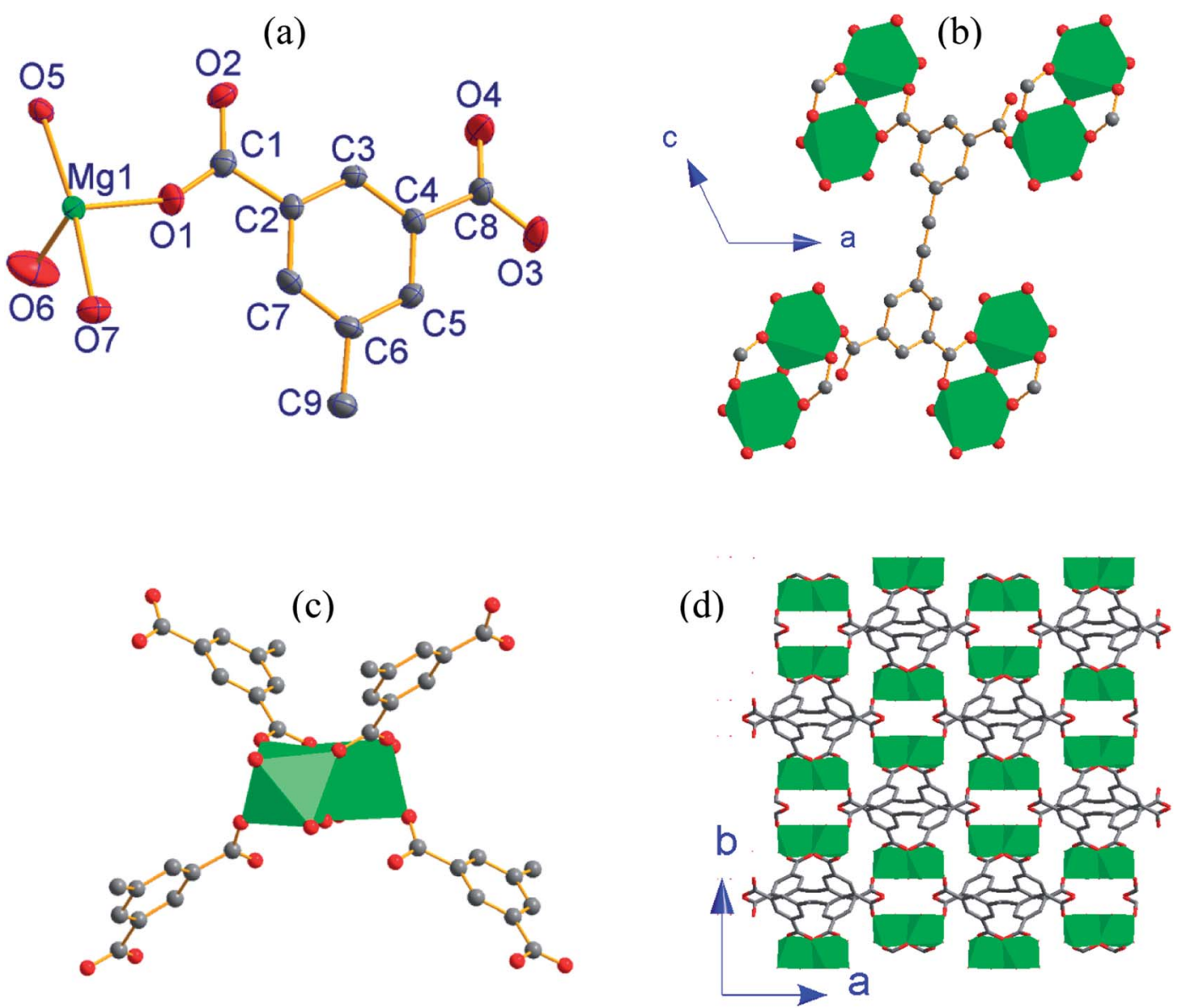

Fig. 3 (a) An asymmetric unit of 3 with thermal ellipsoids drawn at 50\% probability level; (b) connectivity of EBTC ${ }^{4-}$ ligand; (c) connectivity of binuclear cluster as SBU; (d) 3-D packing framework viewed along the c-axis (all H atoms are omitted for clarity) in 3.

well as $\mu_{2}-\eta^{2}: \eta^{1}$ in $2 . \mathrm{H}_{2}$ EBTC $^{2-}$ acts as a $\mu_{2}$-bridging ligand in $\mathbf{1}$; HEBTC $^{3-}$ serves as a $\mu_{6}$-bridging ligand in 2 , and EBTC $^{4-}$ also acts as a $\mu_{6}$-bridging ligand in 3 . Thus, the different deprotonation degrees of the carboxylic groups can facilitate the modification of coordination types, leading to the assembly of metal-organic nets with different structures. In addition, the dihedral angles between the two phenyl rings in the $\mathrm{H}_{2} \mathrm{EBTC}^{2-} / \mathrm{HEBTC}^{3-} / \mathrm{EBTC}^{4-}$ ligand vary from $1.3^{\circ}$ to $83.8^{\circ}$ in $\mathbf{1 - 3}$, indicating that strong spatialdistortion effects exist for the $\mathrm{H}_{2}$ EBTC $^{2-} /$ HEBTC $^{3-} /$ EBTC $^{4-}$ ligand, which allow compliance with coordination with $\mathrm{Mg}^{2+}$ ions to accommodate the steric demands of the dense SBUs. This fact demonstrates that the rotation of the two phenyl rings around the $-\mathrm{C} \equiv \mathrm{C}$ - group only needs to overcome a small energy barrier, and such a feature makes the $\mathrm{H}_{2}$ EBTC $^{2-} / \mathrm{HEBTC}^{3-} / \mathrm{EBTC}^{4-}$ ligand rather flexible to fit to different coordination modes with the metal centers in the solvothermal process. Therefore, the flexible molecular conformation and various coordination modes of the $\mathrm{H}_{2}$ EBTC $^{2-} / \mathrm{HEBTC}^{3-} / \mathrm{EBTC}^{4-}$ ligand with metal centers result in the structural diversity of 1-3.

\section{Possible role of 2-APA or 4-ABA in the crystal growth}

By comparison of the crystal structures of $\mathbf{1}$ and $\left[\mathrm{Mg}\left(\mathrm{H}_{2}-\right.\right.$ EBTC)(DMF $\left.)_{2}\right]^{25}$ as well as 2 and 3, it is found that SIA 2-APA or 4ABA leads to reduced dimensionality of the crystal structure of the final solvothermal reaction product; e.g., $\left[\mathrm{Mg}\left(\mathrm{H}_{2} \mathrm{EBTC}\right)(\mathrm{DMF})_{2}\right]^{25}$ and 3 show structures with 3-D metal-organic frameworks (without SIA), whereas 1 and 2 display structures with a 1-D
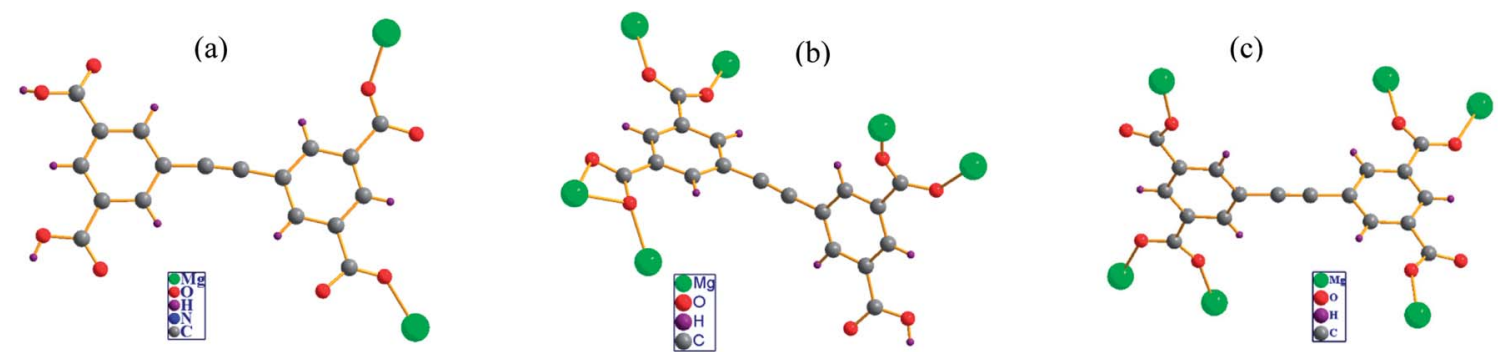

Fig. 4 Coordination modes of the $\mathrm{H}_{2}$ EBTC $^{2-} / \mathrm{HEBTC}^{3-} / \mathrm{EBTC}^{4-}$ ligand observed in the crystal structures of (a) 1 (b) 2 and (c) 3. 
Table 3 Photophysical parameters for $\mathrm{H}_{4}$ EBTC and 1-3 at $298 \mathrm{~K}$

\begin{tabular}{llllll}
\hline Compound & $\lambda_{\mathrm{ex}} / \mathrm{nm}$ & $\lambda_{\mathrm{em}} / \mathrm{nm}$ & $\tau_{\mathrm{f}} / \mathrm{ns}$ & $\phi_{\mathrm{f}} / \%$ & $\mathrm{CIE}$ \\
\hline $\mathbf{1}$ & 330 & 427 & 4.58 & 3.6 & $0.1459,0.0753$ \\
$\mathbf{2}$ & 347 & 423 & 3.66 & 8.8 & $0.1555,0.0506$ \\
$\mathbf{3}$ & 350 & 431 & 3.33 & 7.8 & $0.1538,0.0657$ \\
$\mathrm{H}_{4}$ EBTC & 278 & 392 & - & 0.1 & $0.1592,0.0205$
\end{tabular}

coordination polymer chain (with 2-APA at $85{ }^{\circ} \mathrm{C}$ ) and 2-D coordination layer (with 4-ABA at $110{ }^{\circ} \mathrm{C}$ ), respectively, which presents a good case of SIA effects. At the present stage, it remains unclear what exactly is the critical role played by 2-APA or 4-ABA in the formation process of the crystal structures of 1 or 2 . It is wellknown that the formation of single crystals includes two steps of important processes, namely, initial formation and growth of nuclear crystals. It is impressive that zwitterionic surfactants are widely used for tuning the morphology of nanocrystals during the process of crystal growth in the nanomaterial area, and the surfactants prefer to selectively adsorb on some certain crystallographic planes, which prevents further growth of the adsorbed crystallographic planes to give the special morphology of the nanocrystals. The zwitterionic 2-APA or 4-ABA induces the generation of a new crystal structure under almost the same solvothermal reaction conditions, demonstrating that the 2-APA or 4ABA molecules certainly participate in the initial formation process of nuclear crystals. Notably, with respect to the crystal structure dimensionalities of $\left[\mathrm{Mg}\left(\mathrm{H}_{2} \mathrm{EBTC}\right)(\mathrm{DMF})_{2}\right]^{25}$ and 3 obtained in the absence of 2-APA or 4-ABA, the crystal structure dimensionalities of 1 and 2, which are achieved in the presence of 2-APA or 4-ABA, are reduced, and this finding reveals that the $\mathrm{H}$-bonding interactions between the carboxylates in the $\mathrm{H}_{2} \mathrm{EBTC}^{2-}$ ligand and the protonated amino groups in 2-APA or 4-ABA probably play a specific role in the crystal nucleation process. Such types of $\mathrm{H}$ bonding interactions prevent the carboxylate groups of
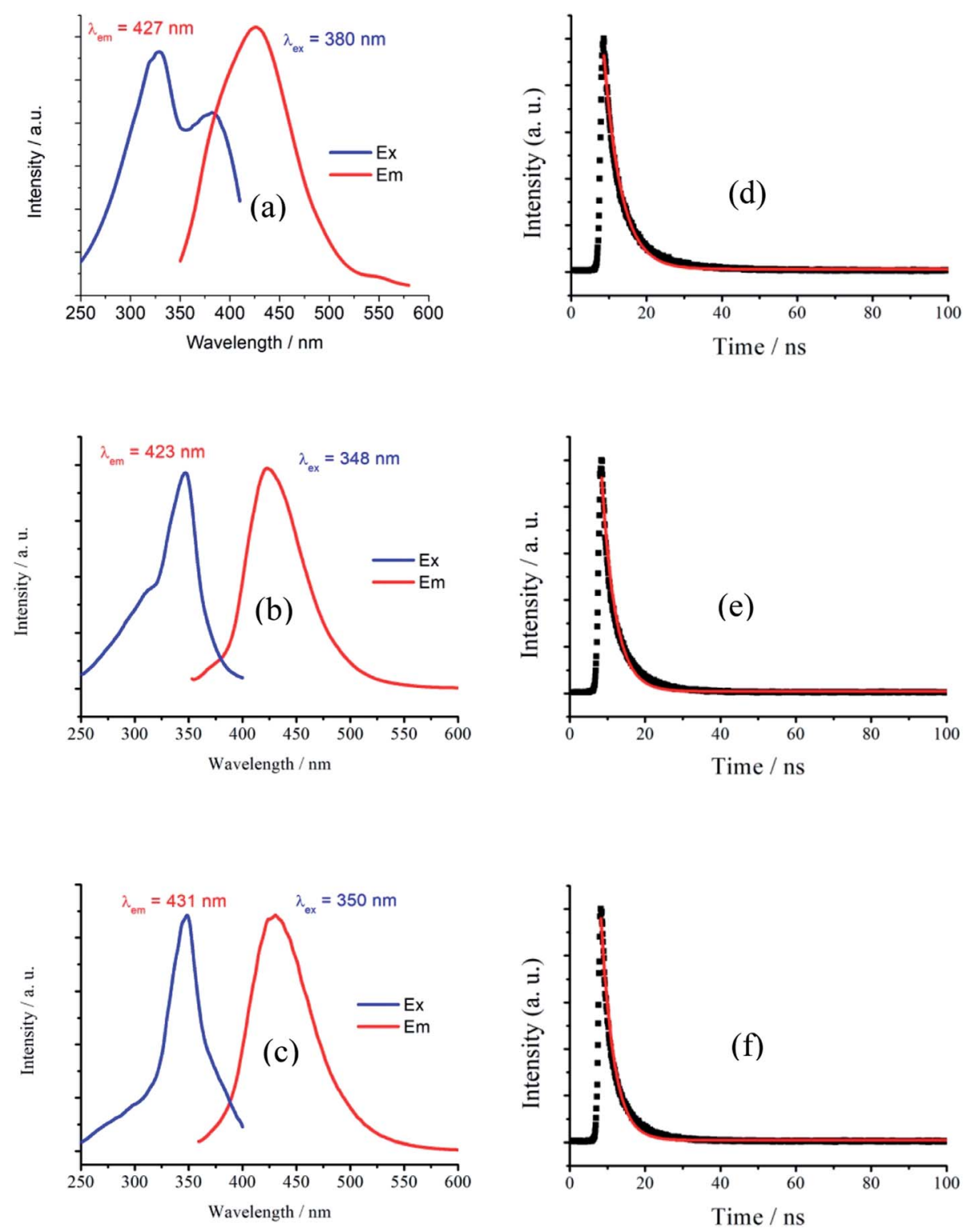

Fig. 5 Excitation and emission spectra of (a) 1 (b) 2 (c) 3 and emission decay curves of (d) 1 (e) 2 (f) 3 in the solid state at 298 K. 
$\mathrm{H}_{2}$ EBTC $^{2-} / \mathrm{HEBTC}^{3-}$ ligand from further coordinating to $\mathrm{Mg}^{2+}$ ions to form the crystal structure with higher dimensionality.

\section{Photoluminescent spectra and photophysical property}

The solid-state photoluminescent (PL) properties of 1-3 together with that of the ligand $\mathrm{H}_{4}$ EBTC were investigated for powdered samples at room temperature including the excitation and emission spectra, photoluminescence decay time and absolute quantum yields. The corresponding spectroscopic and photophysical parameters are summarized in Table 3. In Fig. 5, the emission spectra in the solid state at $298 \mathrm{~K}$ show intense luminescence with an emission band centered at 427, 423 and $431 \mathrm{~nm}$ for 1-3, and the corresponding Commission Internacionale de I'Eclairage (CIE) coordinates are ca. (0.1459, $0.0753),(0.1555,0.0506)$ and $(0.1538,0.0657)$ for $1-3$, indicating that 1-3 show blue luminescence. These results are in good agreement with the luminescent images of the polycrystalline powders of 1-3 obtained under ultraviolet light with $\lambda_{\mathrm{ex}}=330$ $380 \mathrm{~nm}$ at ambient conditions, as shown in Fig. 6.

It is noted that the centers of the emission bands in 1-3 are close to that in the emission spectrum of $\mathrm{H}_{4}$ EBTC in solid state, which is due to intraligand $\pi-\pi^{*}$ electron transition. By comparison of the observations of the emission spectrum of $\mathrm{H}_{4}$ EBTC in solid state, the maximum of band redshifts $c a$. 35, 31 and $39 \mathrm{~nm}$ in the emission spectra of 1-3, respectively, demonstrating that the formation of $\mathrm{Mg}-\mathrm{O}$ coordination bonds affects the electronic structure of the $\mathrm{H}_{4}$ EBTC ligand. These spectral differences may be ascribed to different packing fashions of the organic units between CPs and pristine molecular solid. The emission lifetimes are further investigated, and the corresponding luminescence decay curves are displayed in Fig. $5 \mathrm{~d}-\mathrm{f}$, respectively. The best fits using
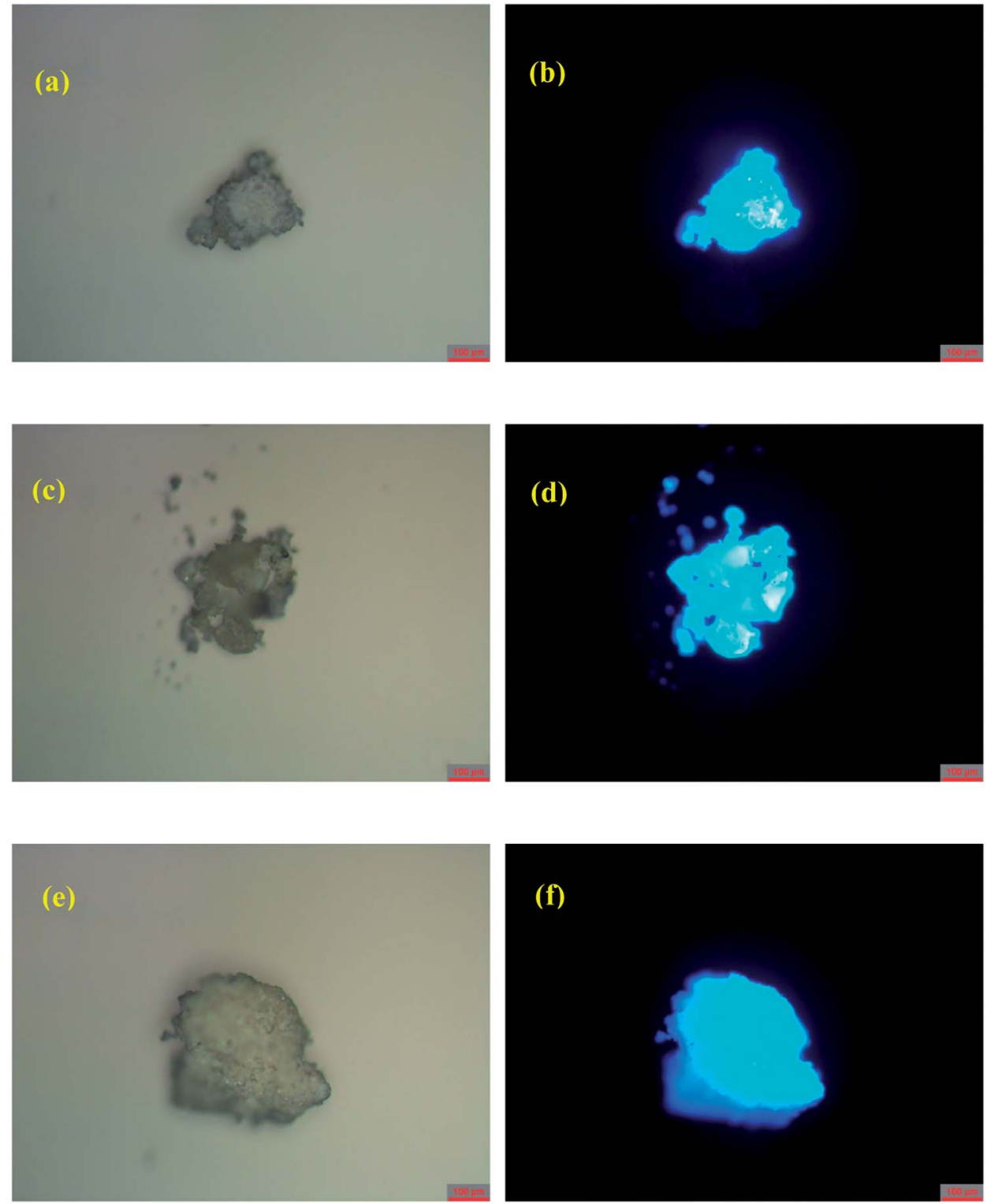

Fig. 6 Photos of powders of 1-3 under ( $a, c$ and e) ambient light and (b, $d$ and f) ultraviolet irradiation with $\lambda_{\mathrm{em}}=340-380 \mathrm{~nm}$, respectively, at room temperature. 
a single exponent equation give the emission decay lifetimes of $4.58 \mathrm{~ns}$ for $\mathbf{1}, 3.66 \mathrm{~ns}$ for 2 and $3.33 \mathrm{~ns}$ for 3 ; all these values fall within the time scales of typical fluorescence decay lifetimes of conjugated organic molecules, indicating that the emission in 1-3 corresponds to the electron transition between the $S_{1}$ and $S_{0}$ states of the phenyl rings in the partly/fully deprotonated $\mathrm{H}_{4}$ EBTC ligand. Besides, the absolute quantum yields are determined by means of the integrating sphere technique and under the excitation light with wavelengths of $330 \mathrm{~nm}, 347 \mathrm{~nm}$ and $350 \mathrm{~nm}$ for 1-3, and the absolute quantum yields are 3.6, 8.8 and 7.8\%, respectively, at 298 K. As shown in Table 3, the absolute quantum yields of 1-3 are much higher than that of the $\mathrm{H}_{4}$ EBTC ligand, which primarily stems from the hydrogen bonds $/ \pi-\pi$ interactions and the increased rigidity of fluorescent linkers as well as the extended $\pi$ conjugated system due to the coordination effect of metal ions. ${ }^{32}$ The stronger luminescent intensities of $\mathbf{2}$ and $\mathbf{3}$ relative to that of $\mathbf{1}$ are mainly governed by the differences in the bridging modes of the $\mathrm{H}_{2}$ EBTC $^{2-}$ /HEBTC $^{3-} /$ EBTC $^{4-}$ ligand. The $\mathrm{H}_{2}$ EBTC $^{2-}$ moieties behave as $\mu_{2}$-linkers in $\mathbf{1}$, whereas in 2 and 3 , the $\mathrm{H}_{2} \mathrm{EBTC}^{2-}$ / EBTC $^{4-}$ spacers feature an intricate $\mu_{6}$-coordination fashion, which makes the ligand more rigid, allowing decrease in the vibration-induced deactivation. ${ }^{33}$

\section{Conclusion}

In this study, three coordination polymers of magnesium ion with flexible molecular conformations with the $\mathrm{H}_{2} \mathrm{EBTC}^{2-} / \mathrm{HEBTC}^{3-}$ / EBTC $^{4-}$ ligand were synthesized and structurally characterized. The versatile coordination modes of the carboxylate group with the $\mathrm{Mg}^{2+}$ ion as well as the flexible molecular conformation of $\mathrm{H}_{2}$ EBTC $^{2-} /$ HEBTC $^{3-} /$ EBTC $^{4-}$ ligand gave rise to diverse crystal structures. It was discovered that the zwitterionic 2-APA (4-ABA) molecules could induce the generation of a new crystal structure in the reaction system under the same solvothermal conditions, and this situation is probably related to the fact that the zwitterionic 2APA (4-ABA) molecules participate in the initial formation process of nuclear crystals. The current study highlighted the effective tuning of the structures of CPs, which can open new avenues for structure tuning of CPs by structural induction agents. On the other hand, three CPs emitted bright ligand-based luminescence at ambient conditions, and all of them showed much higher absolute quantum yields than $\mathrm{H}_{4}$ EBTC in solid state at ambient conditions; thus, high performance luminescent materials are probably achieved by the rational design of metal coordination polymers, and they have promising applications in display and sensing technique areas.

\section{Conflicts of interest}

There are no conflicts to declare.

\section{Acknowledgements}

The authors thank the Priority Academic Program Development of Jiangsu Higher Education Institutions and the National Nature Science Foundation of China (grant no. 21671100 and 51173075) for their financial support.

\section{References}

1 B.-L. Chen, S.-C. Xiang and G.-D. Qian, Acc. Chem. Res., 2010, 43, 1115-1124.

2 Z.-Z. Shi, Z.-R. Pan, L. Qin, J.-L. Zhou and H.-G. Zheng, Cryst. Growth Des., 2017, 17, 2757-2766.

3 B.-Y. Wang, W.-J. Xu, W. Xue, R.-B. Lin, Z.-Y. Du, D.-D. Zhou, W.-X. Zhang and X.-M. Chen, Dalton Trans., 2014, 43, 90089011.

4 Y.-S. Yang, K.-Z. Wang and D.-P. Yan, Chem. Commun., 2017, 53, 7752-7755.

5 X.-Y. Dong, H.-L. Huang, J.-Y. Wang, H.-Y. Li and S.-Q. Zang, Chem. Mater., 2018, 30, 2160-2167.

6 L.-L. Gao, Q.-N. Zhao, M.-M. Li, L.-M. Fan, X.-Y. Niu, X.-Q. Wang and T.-P. Hu, CrystEngComm, 2017, 19, 66516659.

7 N. Wei, M.-Y. Zhang, X.-N. Zhang, G.-M. Li, X.-D. Zhang and Z.-B. Han, Cryst. Growth Des., 2014, 14, 3002-3009.

8 L.-Y. Du, H. Wang, G. Liu, D. Xie, F.-S. Guo, L. Hou and Y.-Y. Wang, Dalton Trans., 2015, 44, 1110-1119.

9 (a) R.-P. Ye, X. Zhang, L. Zhang, J. Zhang and Y.-G. Yao, Cryst. Growth Des., 2016, 16, 4012-4020; (b) X.-Y. Dong, C.-D. Si, Y. Fan, D.-C. Hu, X.-Q. Yao, Y.-X. Yang and J.-C. Liu, Cryst. Growth Des., 2016, 16, 2062-2073.

10 W.-J. Shi, L.-Y. Du, H.-Y. Yang, K. Zhang, L. Hou and Y.-Y. Wang, Inorg. Chem., 2017, 56, 10090-10098.

11 L.-N. Zhang, C. Zhang, B. Zhang, C.-X. Du and H.-W. Hou, CrystEngComm, 2015, 17, 2837-2846.

12 X.-Y. Li, Y.-Z. Li, Y. Yang, L. Hou, Y.-Y. Wang and Z. Zhu, Chem. Commun., 2017, 53, 12970-12973.

13 X.-Y. Dong, C.-D. Si, Y. Fan, D.-C. Hu, X.-Q. Yao, Y.-X. Yang and J.-C. Liu, Cryst. Growth Des., 2016, 16, 2062-2073.

14 X.-Y. Li, L.-N. Ma, Y. Liu, L. Hou, Y.-Y. Wang and Z. Zhu, ACS Appl. Mater. Interfaces, 2018, 10, 10965-10973.

15 H.-Y. Li, J. Xu, L.-K. Li, X.-S. Du, F.-A. Li, H. Xu and S.-Q. Zang, Cryst. Growth Des., 2017, 17, 6311-6319.

16 J.-Z. Gu, Y.-H. Cui, X.-X. Liang, J. Wu, D.-Y. Lv and A. M. Kirillov, Cryst. Growth Des., 2016, 16, 4658-4670.

17 Q.-G. Zhai, X.-H. Bu, X. Zhao, C.-Y. Mao, F. Bu, X.-T. Chen and P.-Y. Feng, Cryst. Growth Des., 2016, 16, 1261-1267.

18 Y. Zhao, X.-H. Chang, G.-Z. Liu, L.-F. Ma and L.-Y. Wang, Cryst. Growth Des., 2015, 15, 966-974.

19 V. Chandrasekhar, C. Mohapatra and R. J. Butcher, Cryst. Growth Des., 2012, 12, 3285-3295.

20 Y. Han, Z. Zhang, Y. Liu, Y. Niu, D. Ding, B. Wu, H. Hou and Y. Fan, Cryst. Growth Des., 2011, 11, 3448-3455.

21 (a) S. Noro, J. Mizutani, Y. Hijikata, R. Matsuda, H. Sato, S. Kitagawa, K. Sugimoto, Y. Inubushi, K. Kubo and T. Nakamura, Nat. Commun., 2015, 6, 5851-5859; (b) R. Ochi, S. Noro, Y. Kamiya, K. Kubo and T. Nakamura, Chem.-Eur. J., 2016, 22, 11042-11047.

22 P. Vishnoi, D. Kaleeswaran, A. C. Kalita and R. Murugavel, CrystEngComm, 2016, 18, 9130-9138.

23 S.-L. Cai, Z.-H. He, W.-H. Wu, F.-X. Liu, X.-L. Huang, S.-R. Zheng, J. Fan and W.-G. Zhang, CrystEngComm, 2017, 19, 3003-3016. 
24 L. Zhai, W.-W. Zhang, J.-L. Zuo and X.-M. Ren, Dalton Trans., 2016, 45, 3372-3379.

25 L. Zhai, W.-W. Zhang, J.-L. Zuo and X.-M. Ren, Dalton Trans., 2016, 45, 11935-11938.

26 Y.-X. Hu, S.-C. Xiang, W.-W. Zhang, Z.-X. Zhang, L. Wang, J.-F. Bai and B.-L. Chen, Chem. Commun., 2009, 48, 75517553.

27 APEX 2, SAINT, XPREP, Bruker AXS Inc., Madison, Wisconsin, USA, 2007.

28 SADABS, Bruker AXS Inc., Madison, Wisconsin, USA, 2001.
29 G. M. Sheldrick, SHELXS97 and SHELXL97: Program for the Refinement of Crystal Structure, University of GÖttingen, Germany, 1997.

30 A. L. Spek, J. Appl. Crystallogr., 2003, 36, 7-13.

31 P. V. D. Sluis and A. L. Spek, Acta Crystallogr., Sect. A: Found. Crystallogr., 1990, 46, 194-201.

32 X. Zhang, L. Fan, Z. Sun, W. Zhang, D. Li, J. Dou and L. Han, Cryst. Growth Des., 2013, 13, 792-803.

33 D. Sun, L. L. Han, S. Yuan, Y. K. Deng, M. Z. Xu and D. F. Sun, Cryst. Growth Des., 2013, 13, 377-385. 